\title{
Effects of pulmonary rehabilitation on exercise capacity in patients with COPD: A number needed to treat study
}

This article was published in the following Dove Press journal:

International Journal of COPD

20 August 2009

Number of times this article has been viewed

\section{Gian Galeazzo Riario-Sforza' \\ Cristoforo Incorvaia' \\ Fulvia Paterniti' \\ Laura Pessina' \\ Roberta Caligiuri ${ }^{1}$ \\ Chiara Pravettoni' \\ Fabiano Di Marco² \\ Stefano Centanni ${ }^{2}$}

'Pulmonary rehabilitation, Istituti Clinici di Perfezionamento, Milan, Italy; ${ }^{2}$ Unit of Respiratory Medicine, University of Milan, San Paolo

Hospital, Milan, Italy
Correspondence: Cristoforo Incorvaia Pulmonary rehabilitation, ICP Hospital, via Bignami I, 20126 Milan, Italy

Tel +39-0257993289

Fax $+39-02579933$ I 5

Email cristoforo.incorvaia@gmail.com
Background: Pulmonary rehabilitation (PR) is recognized as an evidence-based treatment in improving dyspnea and quality of life in patients with COPD. We evaluated the number needed to treat (NNT) to achieve an increase in physical capacity, as defined by a significant improvement in the six-minute walk test (6MWT) in patients with COPD undergoing PR.

Methods: The study enrolled 284 patients aged 41 to 86 years (mean age 69.4 years) divided into two groups: a study group (222 patients) undergoing a PR program, and a control group (62 patients) treated only with drugs. The study group included patients with COPD divided in four subgroups according to GOLD stages.

Results: In the study group, 142 out of 222 patients (64\%) had an increase of at least $54 \mathrm{~m}$ in the 6MWT following PR versus 8 out of 62 patients $(13 \%)$ in the control group after the same time interval. The NNT in the overall study group was 2 ; the same NNT was obtained in GOLD stages 2, 3, and 4, but was 8 in stage 1 .

Conclusions: PR is highly effective in improving the exercise capacity of patients with COPD, as demonstrated by a valuable NNT, with better results in patients with a more severe disease.

Keywords: chronic obstructive lung disease, exercise capacity, number needed to treat, pulmonary rehabilitation, six-minute walk test

\section{Introduction}

Chronic obstructive pulmonary disease (COPD) causes progressive impairment of airflow and physical capacity. ${ }^{1}$ Measurement of lung function currently establishes the severity of the disease, ${ }^{1}$ while exercise capacity is associated with health-related quality of life. ${ }^{2,3}$ Both functions define the health status in COPD patients and their deterioration is implicated in a decrease of life expectancy, ${ }^{1,4,5}$ with a more strict association reported for physical disability than for lung function. ${ }^{4,6}$ An accepted method to measure exercise capacity is the walk test, which was initially introduced as the distance walked in 12 minutes, ${ }^{7}$ but was later developed and standardized as the six-minute walk test (6MWT). ${ }^{8}$

Pulmonary rehabilitation (PR) is an evidence-based standard of care for COPD patients, recently reviewed in a consensus document. ${ }^{9}$ In this document the statement "A program of exercise training of the muscles of ambulation is recommended as a mandatory component of PR for patients with COPD" is given a $1 \mathrm{~A}$ grade of recommendation. ${ }^{9}$ In assessing the effects of PR on physical performance, the 6MWT test was demonstrated to be an adequate index ${ }^{10}$ and the cut-off indicating significant improvement was established in an increase of $54 \mathrm{~m}$ in respect to the baseline value. ${ }^{11}$ 
This study aimed to analyze the number needed to treat (NNT), that is, the number of patients who need to be treated in order to have one patient with clinically significant benefit, to evaluate the improvement in exercise capacity, as defined by an increase of at least $54 \mathrm{~m}$ in the distance walked during the 6MWT in patients with COPD undergoing PR.

\section{Methods}

\section{Patients}

The study enrolled 291 patients, however seven did not take part due to family problems (three cases), moving (one case), or personal unspecified reasons (three cases). The study population consisted of 284 patients aged between 41 and 86 years (185 males, 122 females, mean age 69.4, standard deviation [SD] 8.3 years). All subjects gave formal consent and the study was approved by the Hospital Ethics Committee. Study subjects were categorized into two groups. The study group was defined as group A. This group was made up of 222 patients aged between 41 and 86 years (149 males, 96 females, mean age 69.2, SD 8.6 years) referred between January and December 2006 to the Pulmonary Rehabilitation Unit of the Istituti Clinici di Perfezionamento of Milan, all undergoing a six-week PR program. The study group included patients with COPD and was divided in four subgroups according to the Global Initiative for chronic Lung Disease (GOLD) stages, based on forced expiratory volume in one second $\left(\mathrm{FEV}_{1}\right)$ values $;{ }^{1}$ group 1 comprised patients with $\mathrm{FEV}_{1}$ not lower than $80 \%$, group 2 patients with $\mathrm{FEV}_{1}$ between $80 \%$ and $50 \%$, group 3 patients with $\mathrm{FEV}_{1}$ between $50 \%$ and $30 \%$, and group 4 patients with $\mathrm{FEV}_{1}$ values lower than $30 \%$.

The control group was defined as group B, consisting of 62 patients aged between 43 and 81 years (36 males, 26 females, mean age 70.3, SD 7.6 years) treated only with pharmacological therapy without any kind of PR. This group included patients for whom PR was planned in subsequent months. They were asked to repeat the 6MWT after six weeks so to have the same time-interval as the study group. In both study and control groups the drug treatment by bronchodilators and, when needed, inhaled corticosteroids was adjusted to optimal dosage and inhalation technique.

\section{Pulmonary rehabilitation}

The program was conducted following a schedule of 12 visits in a six-week period in a day hospital setting. Subjects followed an exercise program using either a cycle ergometer or treadmill, according to the patient's capacity, for 30 minutes; upper-limb and trunk exercise training, with warm-up and limbering exercises focusing on arm, shoulder and trunk muscle groups for 30 minutes; and respiratory muscle training done by low pressure peak expiratory pressure (PEP) using a bottle at 6-8 $\mathrm{cm} \mathrm{H}_{2} \mathrm{O}$ with a $80-\mathrm{cm}$ long, 1-cm wide tube, again for 30 minutes. In addition, patients attended a standard COPD education course, and were taught how to perform muscle exercises and respiratory training every day at home for the entire duration of the program.

\section{Six-minute walk test}

The 6MWT was conducted according to American Thoracic Society (ATS) guidelines ${ }^{8}$ and supervised by qualified technicians, who were not told which group each patient belonged to. In brief, each patient was instructed to walk at his or her own pace along a straight, flat $27 \mathrm{~m}$ hospital corridor marked at both extremities. Heart rate, blood pressure, oxygen saturation, and Borg score (based on an exertion scale where $0=$ no exertion and $10=$ very severe exertion) were measured at the start $(0 \mathrm{~min})$ and at the end (six minutes) of the walk test. Patients were asked to cover as much ground as possible in six minutes but were allowed to stop if they showed symptoms of dyspnea or leg pain. The distance in meters was recorded at the end of the six minutes. The 6MWT was performed immediately before and after PR in the study group and with the same time interval (six weeks) in the control group.

\section{Statistical analysis}

The effectiveness of PR in inducing an improvement of at least $54 \mathrm{~m}$ with the 6MWT was analyzed by the NNT, which is a treatment-specific measurement and demonstrates the difference between treatment and control in achieving a particular outcome. According to its original formulation, ${ }^{12}$ NNT is calculated as the inverse of the absolute risk reduction (ARR), where ARR = control event rate - experimental event rate. NNT value and confidence intervals (CI) for the overall group of patients undergoing PR and for single subgroups defined by COPD severity was analyzed using GraphPad Prism (Graph Pad Software Inc., San Diego, CA, USA).

The rate of patients obtaining the 54-m increase in the different groups was compared by the chi-squared test, setting the significance at $\mathrm{p}<0.05$.

\section{Results}

Table 1 reports the main characteristics of patients at baseline. Considering all patients of group A, 142 out of 222 (64\%) had an increase of at least $54 \mathrm{~m}$ in the 6MWT following PR. 
Table I Main characteristics of patients at baseline

\begin{tabular}{llll}
\hline Group & $\begin{array}{l}\text { FEV } \text { in } \mathbf{~ m L} \\
(\%)\end{array}$ & $\begin{array}{l}\text { SGRQ } \\
\text { Total score }\end{array}$ & $\begin{array}{l}\text { Meters walked } \\
\text { during 6MWT }\end{array}$ \\
\hline Study group & $\begin{array}{l}1219 \pm 465 \\
(54.4 \pm 20.7)\end{array}$ & $53.6 \pm 15.6$ & $296.8 \pm 88.7$ \\
Control group & $1267 \pm 513$ & $51.9 \pm 18.8$ & $301.2 \pm 67.8$ \\
& $(53.8 \pm 13.2)$ & & \\
\hline
\end{tabular}

Abbreviations: FEV , forced expiratory volume at one second; SGRQ, St. George's Respiratory Questionnaire; 6MWT, six-minute walk test.

In group B, 8 out of 62 patients (12.9\%) had an increase of $54 \mathrm{~m}$ in the $6 \mathrm{MWT}$ after the same time interval with no PR. This difference was significant $(\mathrm{p}<0.001)$ with the chi-squared test. In the study subjects, $36 \%$ did not achieve the significant increase, compared to $87.1 \%$ of the control subjects. The absolute risk reduction was $47.5 \%$ (95\% CI: $37.1 \%$ to $57.9 \%)$. The NNT obtained was $2(95 \%$ CI: 1.6 to 2.5 ).

The subgroups of patients in group A were formed as follows: group in GOLD stage 1, 37 patients (24 males, 13 females, mean age $64.6 \pm 9.8$ years, range 41 to 83 years); group in GOLD stage 2, 95 patients (61 males, 34 females, mean age $72.7 \pm 8$ years, range 41 to 86 years); group in GOLD stage 3,47 patients (29 males, 18 females, mean age $67.6 \pm 6.6$. years, range 57 to 82 years); group in GOLD stage 4,43 patients ( 27 males, 16 females, mean age $68 \pm 6.9$ years, range 58 to 86). There were no significant differences in the distribution of males and females in the different groups. Table 2 shows the results of the 6MWT and the NNT values in the subgroups of patients. The difference in the number of patients obtaining a 54-m increase versus control group was nonsignificant for group 1, but significant for groups 2,3 , and 4 , with a $p$ value $<0.001$ in each group.

\section{Discussion}

The impairment of exercise capacity in patients with COPD is a central issue in the natural history of this disease. ${ }^{1} \mathrm{~A}$ recent study reported that in more severe GOLD stages of COPD there is an higher decrease in exercise capacity than in $\mathrm{FEV}_{1}$ predicted values, ${ }^{13}$ which however remains the parameter classifying the severity of COPD. ${ }^{1}$ The six-minute walk distance (6MWD) is an accepted method to measure exercise capacity, ${ }^{8}$ which was also recently validated by mathematical models. ${ }^{5}$ By such test, an increase of $54 \mathrm{~m}$ from the baseline value is considered a significant improvement in physical capacity. $^{11}$

PR is a valuable treatment for COPD patients. ${ }^{14,15}$ The evidence-based clinical practice guidelines by the Joint Commission of the American College of Chest Physicians (ACCP) and the American Association of Cardiovascular and Pulmonary Rehabilitation (AACVPR) stated 25 evidence-based recommendations. ${ }^{9}$ These statements include the capacity of PR to improve the symptoms of dyspnea (grade 1A) and the health-related quality of life (grade 1A), but no statement concerns the improvement of physical capacity. In fact, studies on this particular issue reported different observations: in 1999 a meta-analysis detected a significant improvement in the 6MWD after PR, corresponding to a mean value of $49 \mathrm{~m} ;{ }^{16}$ in a more recent Cochrane systematic review, which included 16 trials, a very similar but not significant increase of $48 \mathrm{~m}$ was found. ${ }^{17}$ In any case, both values were below the threshold of clinical significance, ie, the $54 \mathrm{~m}$ increase.

In the present study, considering the overall population of patients undergoing PR, the mean distances walked before and after PR were $296.8 \mathrm{~m}$ and $384.7 \mathrm{~m}$, respectively, corresponding to a mean increase of $87.9 \mathrm{~m}$, which is above the threshold of clinical significance. The lesser heterogeneity of our patients in respect to the meta-analyses, which included different studies, may account for such a finding. Analyzing the difference according to COPD severity, stage 1 of disease had the lower increase $(63 \mathrm{~m})$, while the increase in walked distance was $68.5 \mathrm{~m}$ for stage 2, $89.1 \mathrm{~m}$ for stage 3 , and $132 \mathrm{~m}$ for stage 4 . It has been reported that females have a higher $6 \mathrm{MWD},{ }^{5}$ which could possibly influence the results of global analyses, but in our groups there were no significant

Table 2 NNT in the subgroups of different GOLD stages

\begin{tabular}{llllll}
\hline Subgroup & $\begin{array}{l}\text { Meters walked before } \\
\text { PR (mean } \pm \text { SD) }\end{array}$ & $\begin{array}{l}\text { Meters walked after } \\
\text { PR (mean } \pm \text { SD) }\end{array}$ & $\begin{array}{l}\text { No of patients with } \\
\mathbf{a} \mathbf{5 4} \text { m increase }\end{array}$ & NNT & $\mathbf{9 5 \%}$ Cl \\
\hline GOLD I & $355 \pm 63$ & $418 \pm 78$ & $10 / 37$ & 8 & -2.4 to 30.7 \\
GOLD 2 & $324.8 \pm 102.3$ & $393.3 \pm 82.5$ & $60 / 95$ & 2 & 1.6 to 2.7 \\
GOLD 3 & $327.4 \pm 117.1$ & $416.5 \pm 102.7$ & $33 / 47$ & 2 & 1.4 to 2.4 \\
GOLD 4 & $180 \pm 60.7$ & $312 \pm 81.1$ & $39 / 43$ & 2 & 1.1 to 2.5 \\
\hline
\end{tabular}

Abbreviations: $\mathrm{Cl}$, confidence interval; GOLD, Global Initiative for Chronic Obstructive Pulmonary Disease; NNT, number needed to treat; PR, pulmonary rehabilitation; $\mathrm{SD}$, standard deviation. 
differences in the distribution of females in the different groups. However, the aim of the study was to evaluate by NNT the effectiveness of PR in improving the physical capacity in COPD patients. This statistical analysis was introduced in 1988 as a measure able to assess more precisely the consequences of a medical treatment, ${ }^{12}$ and was initially greeted with enthusiasm ${ }^{18}$ but was later the object of some criticism. ${ }^{19}$ In particular, when measuring the effectiveness of interventions targeting chronic diseases, NNT varies over time and thus does not capture the crucial time component. ${ }^{19}$ For example, in analyzing the effectiveness of finasteride for the treatment of benign prostatic hyperplasia, the NNT for avoiding prostate-related surgery was 31 (21 to 61) over 24 months but was 18 (14 to 27 ) over 48 months. ${ }^{20}$

In our study the time bias was not present as the NNT was calculated after the first cycle of PR, the only point when the comparison with baseline values can be made. Subsequent cycles generally maintain improved exercise capacity, ${ }^{21-23}$ but further increases over the threshold of clinical significance are not expected.

Some studies have used the NNT to evaluate the outcome of pulmonary rehabilitation in COPD patients: a recent meta-analysis of six trials which included 219 patients undergoing PR after exacerbations of COPD found a NNT of 3 in reducing subsequent hospital admissions and of 6 in reducing mortality. ${ }^{24}$ In a Canadian study, NNT was calculated by focusing on the quality of life assessed by the Chronic Respiratory Questionnaire (CRQ) and ranged from 2.5 for mastery to 4.4 for fatigue. ${ }^{25}$ Regarding the $6 \mathrm{MWT}$, the improvement is generally analyzed calculating the difference in the mean distance walked ${ }^{17}$ and only one study, to the best of our knowledge, analyzed the NNT. ${ }^{26}$ This particular study evaluated 34 patients with stable COPD receiving a PR program for six months versus 28 patients receiving usual medical care, and found a NNT of 3 . The NNT obtained in the present study, including 222 patients versus 62 controls, was 2 . The different time intervals in the two studies - six months versus six weeks - is likely to account for the difference, taking into consideration that, in the study by Troosters and colleagues, ${ }^{26}$ the most intense training was done in the first three months.

Dividing the patients into the GOLD severity stages, we found a different result in patients with initial stage - NNT corresponding to 8 - compared to patients with advances stages, in whom the NNT was 2 . We did not include the GOLD stage 0 in our analysis, which is considered in the initial classification of severity, but not in the last update of GOLD guidelines. ${ }^{27}$ The significance of the observation is that in mild stage of COPD, with a $\mathrm{FEV}_{1}$ value not lower than $80 \%$ of predicted, eight patients must be treated by PR to have one patient with a significant increase of exercise capacity. This confirms the current indication to apply PR in COPD patients starting from the GOLD stage $2 .^{9}$

In conclusion, this study found that a PR program with physical training, upper-limb and trunk exercise training, and respiratory muscle training is highly effective in improving the exercise capacity of patients with COPD, as demonstrated by a NNT of 2 .

\section{Disclosures}

This trial is registered at Eudract; protocol number ICP001. The authors report no conflicts of interest in this work. The authors thank Miss Laura Jane Shearer for English language revision.

\section{References}

1. Pauwels RA, Buist AS, Calverley PM, et al. GOLD Scientific Committee: Global strategy for the diagnosis, management and prevention of chronic obstructive pulmonary disease. NHLBI/WHO Global Initiative for Chronic Obstructive Pulmonary Disease (GOLD) Workshop summary. Am J Respir Crit Care Med. 2001;163:1256-1276.

2. Jones PW, Quirk FH, Baveystock CM, et al. A self-complete measure of health status for chronic airflow limitation: the St. George's Respiratory Questionnaire. Am Rev Respir Dis. 1992;145:1321-1327.

3. Engstrom CP, Persson LO, Larsson S, et al. Functional status and well being in chronic obstructive pulmonary disease with regard to clinical parameters and smoking: a descriptive and comparative study. Thorax. 1996;51:825-830

4. Pinto-Plata VM, Cote C, Cabral H, et al. The 6-min walk distance: change over time and value as a predictor of survival in severe COPD. Eur Respir J. 2004;23:28-33.

5. Cote CG, Casanova C, Marin JM, et al. Validation and comparison of reference equations for the 6-min walk distance test. Eur Respir J. 2008;31:571-578.

6. Oga T, Nishimura K, Tsukino M, et al. Analysis of the factors related to mortality in chronic obstructive pulmonary disease: role of exercise capacity and health status. Am J Respir Crit Care Med. 2003;167: 449-544.

7. McGavin CR, Gupta SP, McHardy GJ. Twelve-minute walking test for assessing disability in chronic bronchitis. Br Med J. 1976;1:822-823.

8. ATS Committee on Proficiency Standards for Clinical Pulmonary Function Laboratories. ATS Statement: guidelines for the six-minute walk test. Am J Respir Crit Care Med. 2002;166:111-117.

9. Ries AL, Bauldoff GF, Carlin BV, et al. Pulmonary rehabilitation: joint ACCP/AACVPR evidence-based clinical practice guidelines. Chest. 2007;131(Suppl 5):4-42.

10. Votto J, Bowen J, Scalise P, et al. Short-stay comprehensive inpatient pulmonary rehabilitation for advanced chronic obstructive pulmonary disease. Arch Phys Med Rehabil. 1996;77:1115-1118.

11. Redelmeyer DA, Bayoumi A, Goldstein RS, et al. Interpreting small differences in functional status: the six minute walk test in chronic lung disease patients. Am J Respir Crit Care Med. 1997;155:1278-1282.

12. Laupacis A, Sackett DL, Roberts RS. An assessment of clinically useful measures of the consequence of treatment. $N$ Engl J Med. 1988;318:1728-1733.

13. Casanova C, Cote CG, Marin JM, et al. The 6-minute walking distance: long-term follow up in patients with COPD. Eur Respir J. 2007; 29:535-540. 
14. Troosters T, Casaburi R, Gosselink R, et al. Pulmonary rehabilitation in chronic obstructive pulmonary disease. Am J Respir Crit Care Med. 2005;172:19-38

15. Nici L, Donner C, Wouters E, et al. American Thoracic Society/ European Respiratory Society statement on pulmonary rehabilitation. Am J Respir Crit Care Med. 2006;173:1390-1413.

16. Cambach W, Wagenaar RC, Koelman TW, et al. The long-term effects of pulmonary rehabilitation in patients with asthma and chronic obstructive pulmonary disease: a research synthesis. Arch Phys Med Rehabil. 1999;80:103-111.

17. Lacasse Y, Martin S, Lasserson TJ, et al. Meta-analysis of pulmonary rehabilitation for chronic obstructive pulmonary disease. Eura Medicophys. 2007;43:475-485.

18. Cook RJ, Sackett DL. The number needed to treat: a clinically useful measure of treatment effect. BMJ. 1995;10:452-454.

19. Christensen PM, Kristiansen IS. Number needed to treat (NNT) - Needs treatment with care. Basic Clin Pharmacol Toxicol. 2006;99:12-16.

20. Edwards JE, Moore RA. Finasteride in the treatment of clinical benign prostatic hyperplasia: a systematic review of randomised trials. $B M C$ Urol. 2002;2:14-31.
21. Guell R, Casan P, Belda J, et al. Long-term effects of outpatients rehabilitation of COPD: a randomized trial. Chest. 2000;117:976-983.

22. Ries AL, Kaplan RM, Myers R, et al. Maintenance after pulmonary rehabilitation in chronic lung disease: a randomized trial. Am J Respir Crit Care Med. 2003;167:880-888.

23. Foglio K, Bianchi L, Bruletti G, et al. Seven-year time of lung function, symptoms, health-related quality of life, and exercise tolerance in COPD patients undergoing pulmonary rehabilitation programs. Respir Med. 2007;101:1961-1970.

24. Puhan M, Scharplatz M, Trosteers T, et al. Pulmonary rehabilitation following exacerbations of chronic obstructive pulmonary disease. Cochrane Database Syst Rev. 2009;1:CD0055305.

25. Goldstein RS, Gort EH, Guyatt GH, et al. Economic analysis of respiratory rehabilitation. Chest. 1997;112:370-379.

26. Troosters T, Gosselink R, Decramer M. Short- and long-term effect of outpatient rehabilitation in patients with chronic obstructive pulmonary disease: a randomised trial. Am J Med. 2000;109:207-212.

27. Global Initiative for Chronic Obstructive Lung Disease. Global Strategy for Diagnosis, Management, and prevention of COPD, updated December 2007. Available at http:/goldcopd.org/. Accessed August 22, 2008.
International Journal of COPD

\section{Publish your work in this journal}

The International Journal of COPD is an international, peer-reviewed journal of therapeutics and pharmacology focusing on concise rapid reporting of clinical studies and reviews in COPD. Special focus is given to the pathophysiological processes underlying the disease, intervention programs, patient focused education, and self management protocols.

\section{Dovepress}

This journal is indexed on PubMed Central, MedLine and CAS. The manuscript management system is completely online and includes a very quick and fair peer-review system, which is all easy to use. Visit http://www.dovepress.com/testimonials.php to read real quotes from published authors. 